\title{
Coulisses
}

Revue de théâtre

19 | Hiver 1999

Varia

\section{Aberrations du documentaliste}

Conception et mise en scène : François Tomsu et Ezéchiel Garcia-Romeu

- Avec : Jacques Fornier - Nouveau Théâtre, CDN de Besançon Novembre 1998

Stéphane Besson

\section{OpenEdition}

\section{Journals}

Édition électronique

URL : https://journals.openedition.org/coulisses/5431

DOI : $10.4000 /$ coulisses.5431

ISSN : 2546-9460

\section{Éditeur}

Presses universitaires de Franche-Comté

\section{Édition imprimée}

Date de publication : 1 janvier 1999

Pagination : 20

ISBN : 2-913322-09-3

ISSN : $1150-594 \mathrm{X}$

Référence électronique

Stéphane Besson, «Aberrations du documentaliste », Coulisses [En ligne], 19 | Hiver 1999, mis en ligne le 18 octobre 2019, consulté le 12 janvier 2022. URL : http://journals.openedition.org/coulisses/5431 DOI : https://doi.org/10.4000/coulisses.5431

Ce document a été généré automatiquement le 12 janvier 2022.

Coulisses 


\title{
Aberrations du documentaliste
}

\author{
Conception et mise en scène : François Tomsu ${ }^{1}$ et Ezéchiel Garcia-Romeu \\ - Avec : Jacques Fornier ${ }^{2}$ - Nouveau Théâtre, CDN de Besançon - \\ Novembre 1998
}

Stéphane Besson

1 Ce jour-là, pour parvenir jusqu'à lui, les spectateurs durent monter sur la scène du Nouveau Théâtre, emprunter en file indienne la spirale d'un sombre corridor, au centre de laquelle ils découvrirent son alcôve, son antre : un bureau, des chaises les attendant, entourées de murailles de livres en trompe-l'œil... sans oublier le documentaliste luimême. Rien d'autre. Mais «ma demeure est aussi grande que n'importe quelle autre planète. Parce que je suis de la taille de la maison du monde et non de la taille de mon corps. » (Dixit le vieil homme.)

2 Lieu de surprises nombreuses que cette demeure-bibliothèque-planète. Apparaissent et disparaissent des marionnettes, un crâne, un globe (terrestre ?), plusieurs sphères et autres objets. L'échelle des choses est sujette à caution : la taille des sphères varie, un mouchoir de soie devient un grand drap, l'homme côtoie les marionnettes. Peu à peu se dégage l'idée étourdissante d'un univers gigogne dont les éléments s'emboîtent à l'infini : le monde contient la bibliothèque du documentaliste, mais ses livres et sa science contiennent le monde, et son bureau est même un monde dans le monde (ainsi qu'une scène dans la scène du spectacle, elle-même incluse dans le plateau du Nouveau Théâtre... Vertige !), un monde qui communique avec le nôtre par les trappes de sa surface, livrant passage aux magnifiques marionnettes de François Tomsu et Ezéchiel Garcia-Romeu, et engloutissant les grossières figurines de bois et d'argile brandies par le documentaliste, deux représentations de l'homme diamétralement opposées.

3 Sommes-nous dedans ou dehors? Enfermés sous le crâne labyrinthique d'un vieux savant à l'esprit érodé, ou perchés sur les hauteurs sublimes de la connaissance, d'où les démiurges contemplent la création? Assistons-nous à une cérémonie mystique, aux expériences d'un scientifique, aux hallucinations d'un fou?... Peut-être ces termes sont-ils synonymes, peut-être n'ont-ils plus aucun sens, car le langage même du documentaliste dérape et s'égare peu à peu. « Qu'est-ce-fe-ce ? demande-t-il. Qu'est-cefe-ce, la création? » Et plus loin, triomphant : « Conclusion : rore ! R-O-R-E. » 
4 De par l'ambiguïté profonde du texte, de par le décor et la mise en scène qui ne se réfèrent à rien d'autre qu'eux-mêmes, mais aussi de par la sobriété et la finesse du jeu de Jacques Fornier, ce spectacle est un lieu ouvert à tous les questionnements et toutes les interprétations. Et surtout, il nous offre cinquante minutes d'humour, de surprises, d'émerveillement et d'un calme divin.

\section{Jacques Fornier}

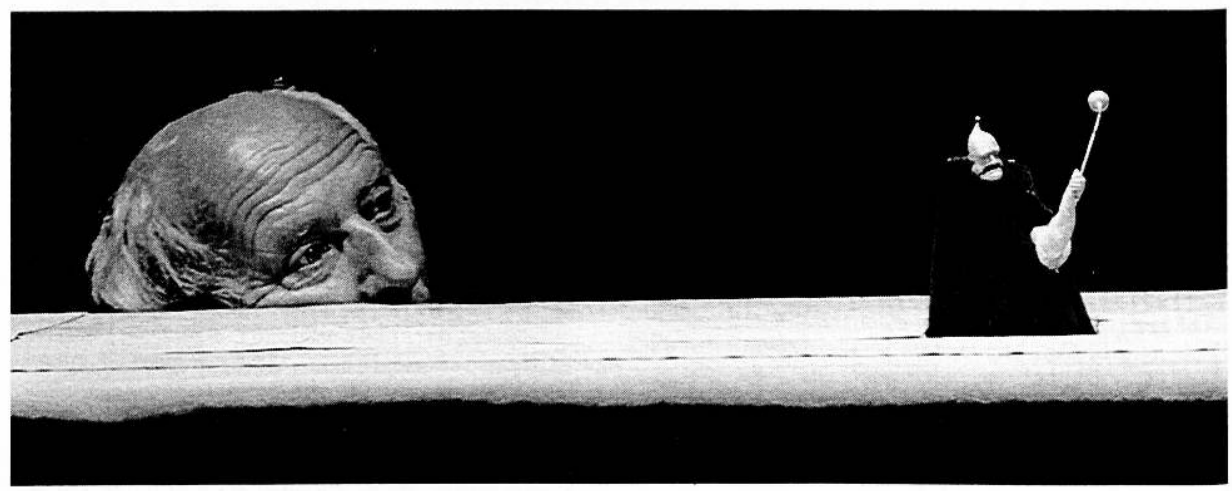

Photo Brigitte Enguerand

\section{NOTES}

1. Que l'on avait pu applaudir dans le rôle principal de Un homme au zoo en décembre 1997. Voir Coulisses $\mathrm{n}^{\circ} 17$.

2. Sur la carrière de ce pilier du théâtre en Franche-Comté, voir son entretien avec Philippe Baron dans Coulisses $n^{\circ} 7$.

\section{AUTEURS}

\section{STÉPHANE BESSON}

TUFC 